Article

\title{
Does Adding Local Tree Elements into Dwellings Enhance Individuals' Homesickness? Scenario-Visualisation for Developing Sustainable Rural Landscapes
}

\author{
Shuping Huang ${ }^{1,2,3,4}$, Cecil Konijnendijk van den Bosch ${ }^{2,4}$, Weicong Fu ${ }^{1,2,3,4}$, Jinda Qi ${ }^{5}$, \\ Ziru Chen ${ }^{1}$, Zhipeng Zhu ${ }^{1}$ and Jianwen Dong ${ }^{1, *}$ \\ 1 College of Landscape Architecture, Fujian Agriculture and Forestry University, \\ Fuzhou 350002, Fujian, China; shupinghuang90@alumni.ubc.ca (S.H.); 2141775001@fafu.edu.cn (W.F.); \\ 2171775002@fafu.edu.cn (Z.C.); 1171775013@fafu.edu.cn (Z.Z.) \\ 2 Urban Forestry Research in Action, Department of Forest Resources Management, The University of British \\ Columbia, Vancouver, BC V6T 1Z4, Canada; cecil.konijnendijk@ubc.ca \\ 3 Collaborative for Advanced Landscape Planning, Faculty of Forestry, The University of British Columbia, \\ Vancouver, BC V6T 1Z4, Canada \\ 4 Faculty of Forestry, The University of British Columbia, Vancouver, BC V6T 1Z4, Canada \\ 5 Faculty of Built Environment, University of New South Wales, Sydney 2052, Australia; \\ jinda.qi@student.unsw.edu.au \\ * Correspondence: fjdjw@fafu.edu.cn; Tel.: +86-133-1377-6679
}

Received: 15 October 2018; Accepted: 27 October 2018; Published: 30 October 2018 updates

\begin{abstract}
Rural residential settings are important elements of livable and sustainable rural areas across the world. Enhancing people's attachment to these landscapes through fostering feelings of homesickness could help in the pursuit of better rural residential settings. We studied homesickness, an emotion found to be associated with higher place attachment and quality of life, related to rural landscapes in southeast China, looking specifically at the presence and configuration of rural dwellings and trees. We used Photoshop to manipulate different configurations of typical rural dwellings and trees, and three series with twelve types of landscape scenes were generated. We looked at the following six emotional factors linked to homesickness: naturalness; regional culture; identity; psychology; experience; and landscape aesthetics. The analytic hierarchy process (AHP) and semantic differential (SD) methods were used to evaluate the level in which the landscape evoked feelings of homesickness amongst study participants, i.e., a group of university students from different disciplines. Results show that the homesickness emotional response level was higher in most of the simulated landscapes, as compared to the original landscape, and that response levels differed significantly between the three types of visualized landscape configurations. The emotional response level showed differences for manipulated landscape scenes with twelve different trees added to dwellings. Through cluster analysis of the results, we divided trees into three grades of emotional response for each dwelling type. Adding trees thus was found to change the emotional response to the landscape, and different tree configurations with different types of dwellings results in different responses. The study shows that careful design of the rural landscape can help build stronger emotional relations of humans with their local environment, which is a key ingredient for sustainable countryside living.
\end{abstract}

Keywords: landscape preference; rural sustainability; rural residential settings; scene visualization; trees 


\section{Introduction}

\subsection{Challenge of Loss of Homesickness Associated with Rural Landscape}

Rural landscapes are valuable as cultural heritage and natural sites with important scenic qualities. Housing development represents one of the most visible indicators of landscape change [1]. Redevelopment, reconstruction, and related landscape change are recognised as common and complex processes across rural areas. These can result in loss of place attachment, place identity, related feelings of nostalgia, amongst others. When connections between people and the rural living landscape are lost, its sustainability is threatened. Despite recent and rapid urbanization, it is estimated that approximately half of the Chinese population is still living in the countryside, according to the Sixth National Census of the People's Republic of China in 2010 [2]. During the past 20 years of rapid development, rural landscapes in China have experienced dramatic changes, for example due to redevelopment of rural villages. Thousands of new rural dwellings are constructed every year, and rural landscapes are gradually being transformed. Unfortunately, this has resulted in a trend of widespread uniformity and 'sameness-of-place' across the countryside, and many traditional buildings, landscapes, and natural forests in rural areas are being destroyed. This is similar in other parts of the world. In North America, for example, suburbanization processes are transforming rural hometowns into generic 'nontowns', and the loss of place attachment and community identity lead to a particularly negative effects for youth [3]. Large-lot residential development, typical for many rural areas, often compromises rural character of rapidly developing rural areas [4]. Rural landscapes throughout North America, Asia, and Europe are being threatened by new residential development $[5,6]$.

Many rural residents feel a sense of loss associated with such dramatic changes in their landscape [7]. Even worse, because of the loss in local distinctiveness and a diluted uniqueness of regions, the emotional bonds between people and the countryside are weakening. If traditional villages lose their unique features and vitality, then the sustainable protection of the rural landscape loses an important foundation, as people may care less about preservation of these landscapes [8]. The maintaining of strong links with traditional rural landscapes will also be very difficult [2,3]. Too much emphasis has been placed on the modernization of economic functions, and on urbanization and new construction, while ignoring local culture, emotions, neighbourhood space, and the natural environment. As a result, traditional cultural communities are facing disintegration and disappearance, which is a threat to longer-term countryside sustainability and liveability.

These contexts are all strongly linked to the emotion of homesickness as a nostalgic, strong place connection. Thus, more sustainable landscape change requires thoughtful reconstruction of communities of culture, emotions, and values. Rural transformation in China needs to focus more on recognition of important landscape values and homesickness, as well as in search of efforts to conserve the rural roots and landscapes of Chinese culture, rather than the speed of development [6]. Incorporating residents' emotional homesickness in rural landscape transformation and creating recognizable and distinctive rural landscape has become a topic of concern for rural landscape planners and designers.

\subsection{Concept of Homesickness in a Chinese Context}

The Oxford English Dictionary (OED, 2003) defines homesickness as: "sadness caused by the longing for one's home or family during a period of absence". Chinese homesickness is a complex emotion [4], which comprises a mix of nostalgia, topophilia, and place attachment [9] (Figure 1). Psychologist Stephan (2012) mentioned that nostalgia is a mental journey into the past, in which old objects, people, places where they used to live and work, and years passed by are the most common theme of nostalgia [10]. Compared with nostalgia which has more of a time focus, topophilia and place attachment have more of a geographical spatial focus. Place attachment, defined as "the emotional bond between a person and a particular place" [11], is connected to the specific physical and social characteristics of particular places [8]. Topophilia (from Greek topos "place" and -philia, "love of") represents a strong sense of place, which often becomes mixed with the sense of 
cultural identity among certain people and a love of certain aspects of such a place. According to geographer Yi-Fu Tuan, topophilia is usually assumed to exist in a unique geographical landscape and its way of life, which includes natural landscapes and cultural landscapes [12]. Therefore, the Chinese conceptualisation of homesickness has a different geographical and spatial perspective as compared to topophilia or place attachment. It focuses more on human habitat, its historical development, and links with nostalgia. Chinese homesickness is a complex emotion which combines aspects of time, attachment, and nostalgia all connected to a specific place or landscape.

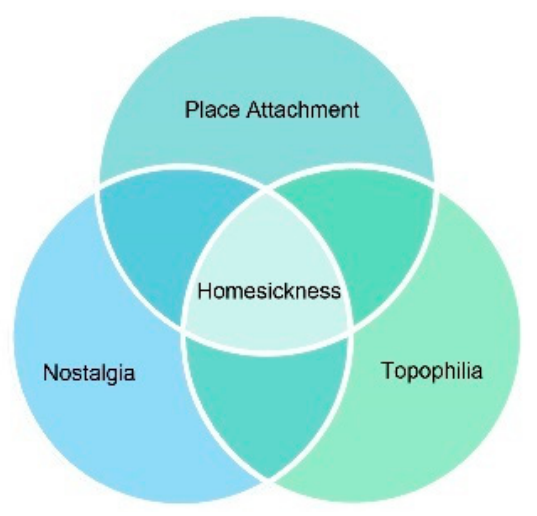

Figure 1. The conceptualization of Chinese homesickness.

\subsection{Development of Chinese Homesickness}

With rapid social changes, the concept of homesickness has had different foci and connotations during the past 100 years (Table 1). This has ranged from a "local sentiment" expressed by scholars and the "patriotism" of overseas Chinese in the 1980s, to the current wider focus on "hometown nostalgia". In the period of 1912-1949, before the establishment of the nation of China, a large number of scholars influenced by Western culture traveled to other countries and studied in big cities. Homesickness in this period mainly related to their longing back to the scholars' hometown or homeland. In 1949-1999, after the establishment of the People's Republic of China, homesickness was primarily expressed by overseas Chinese, and was associated with the feelings of home, country, and hometown. In particular the improvement of cross-strait relations between Taiwan and the mainland in the 1980s brought back eager yearnings for overseas travelers. During the first part of the new millennium, homesickness has related to, on the one hand, a continuation of the nostalgia of overseas Chinese in the 1980s. On the other hand, it embodies a new phenomenon, as with rapid economic globalization and the development of urbanization a large number of migrant workers and urban immigrants emerged. The mainstay of the homesickness concept has gradually transformed into that of ordinary residents, implying a shift away from the focus on literary elites. Many scholars have pointed out the contradiction between modernity and homesickness, and the significance of homesickness in constructing for "immigrant" cultural identity $[13,14]$.

Table 1. Comparison of background and subjects in the history of homesickness in China.

\begin{tabular}{ccccc}
\hline Period & Social Backgrounds & Subject & $\begin{array}{c}\text { Emotional } \\
\text { Tendency }\end{array}$ & Keywords \\
\hline $1912-1949$ & $\begin{array}{c}\text { Influence of western } \\
\text { culture; World war }\end{array}$ & Scholar (study) & Homeland & Travel, Love, Dilemma \\
\hline 1949-1999 & $\begin{array}{c}\text { Establishment of PRC; } \\
\text { Chinese economic reform }\end{array}$ & $\begin{array}{c}\text { Overseas Chinese } \\
\text { (live abroad) }\end{array}$ & Patriotism & Taiwan, Mainland \\
\hline 2000-2018 & $\begin{array}{c}\text { Globalization and } \\
\text { Modernization of } \\
\text { Economic Culture; } \\
\text { Urbanization }\end{array}$ & $\begin{array}{c}\text { Mass groups } \\
\text { (Relocating or moving } \\
\text { to another town) }\end{array}$ & Hometown & $\begin{array}{c}\text { Culture, Traditional, } \\
\text { Modernity, Identity, } \\
\text { Urbanization }\end{array}$ \\
\hline
\end{tabular}




\subsection{Human-Trees Interactions in the Landscape}

Over the past decades, many studies have described the emotional links between people and their landscapes. Research has derived from fields such as environmental psychology, sociology, anthropology, geography, urban planning, architecture and planning, ecology, forestry, and even economics [15]. Earlier study of greenspace found that different types of urban natural area users had different types of place attachment [16]. Feldman (1990) proposed that people identify with a type of residential setting, such as neighborhood, suburb, or small town, rather than with a particular place or town [17]. Scholars have found that individuals tend to have a stronger emotional connection to a place with good environmental qualities, such as natural elements and good greenspace design [18]. The environment can influence homesickness emotional ties, improve people's satisfaction and improve their life attitude [19]. Although social elements were considered to be the most consistent predictor of homesickness in most studies, sometimes physical elements may play a more important role [20]. Studies have demonstrated that regional landscape elements may serve to maintain people's homesickness to their living places [21]. People have an attachment to a type of landscape, such as an oak savanna, as well as to a particular place, such as the stand of oak trees in their local park [13]. Once people are leaving their place, they decorate the new settlements with old items [14].

Among many landscape elements, trees are considered as an important homesickness element in residences' life [22]. Firstly, trees were regarded as symbols of sustainability of the family line [23], so they have often been associated with feelings of homesickness as well. Second, trees are of high importance for a culture's collective memory [24]. In China, it is the custom that immigrants brought a branch or sapling from their hometown to a new settle place. After planting it near their new house, formal connection with the new home was established. Thirdly, because of natural disasters, buildings and other structures were ruined, but trees often survived and recorded the stories of a place. Overall, trees have had symbolic and spiritual meanings to people throughout history. Trees are the physical elements that pass homesickness across generations. Studies have explored people's emotional perceptions of rural residential settings, finding higher homesickness attachment levels with the renewed setting, and indicating that a comfortable rural environment can moderate the indirect effect of residential satisfaction $[25,26]$. However, a question which has not often been answered is how to incorporate feelings of homesickness in the development and management of rural landscape, from a perspective of landscape architecture.

\subsection{Study Aim and Research Questions}

Using the central concepts and research introduced above, the present research aims to examine the levels of homesickness associated with different rural residential settings, particularly combining different types and configurations of buildings and trees in the landscape. Development of the means to understand homesickness and the perceptions of the rural dwelling landscape represent a new application, adding to knowledge of the applicability of the concept of place attachment and its measures. Another objective of this study is to explore whether different combinations of buildings and trees lead to different levels of homesickness response. Our hypothesis is that specific combinations of trees and buildings will evoke stronger homesickness feelings as compared to random building and tree configurations in landscape settings. Using a sample of a local residential settings in a village from Fujian Province, Southeast China, this research utilized a survey and photorealistic visualized questionnaire to explore these issues.

\section{Materials and Methods}

\subsection{Survey Design}

This study included two parts. The first was focused on the measurement and evaluation of homesickness emotion in landscape. Semantic differential (SD) method and analytic hierarchy process (AHP) were used, together with cluster analysis, to analyze differences between scenes with different 
dwellings and tree types and configurations. Three levels of emotional response were identified, namely low, medium and high. The reason we used SD method and AHP method is that the SD method is mainly used to measure the emotion by using a series of antonym. However, not all of the adjective factors are of the same importance, so we used the AHP method to calculate the index weight.

The second part of the study applied scenic visualisation as way of studying rural landscape change, and the impact of specific landscape scenes and elements on people's feelings of homesickness. Photos of selected rural landscape scenes were used, as well as manipulated versions to which trees and dwellings were added. Finally, evaluation and data processing. SD scores were multiplied by AHP weight to obtain each participant's score for every picture (reflecting their level of emotional response to the specific landscape scene shown).

\subsection{Part 1 of the Construction of Evaluation}

\subsubsection{Assignment and Evaluation Method}

Evaluation of homesick landscape emotions comprises the measurement and evaluation of subjective emotions aroused by local landscape stimulation, and in its essence, it is a method of measuring the psychology of homesickness. The SD method proposed by Osgood and others [27,28], which is mainly used to describe landscape imagery by using a series of antonym adjectives to measure the feelings of the homesick landscape. The present study uses a five-point scale $(-2 ;-1 ; 0 ; 1 ; 2)$ between bipolar, contrasting adjectives (e.g., unnatural-natural) and a neutral zero point. The poles of SD scales are labelled and the scales' intervals are assumed to be of equal distance (Figure 2).

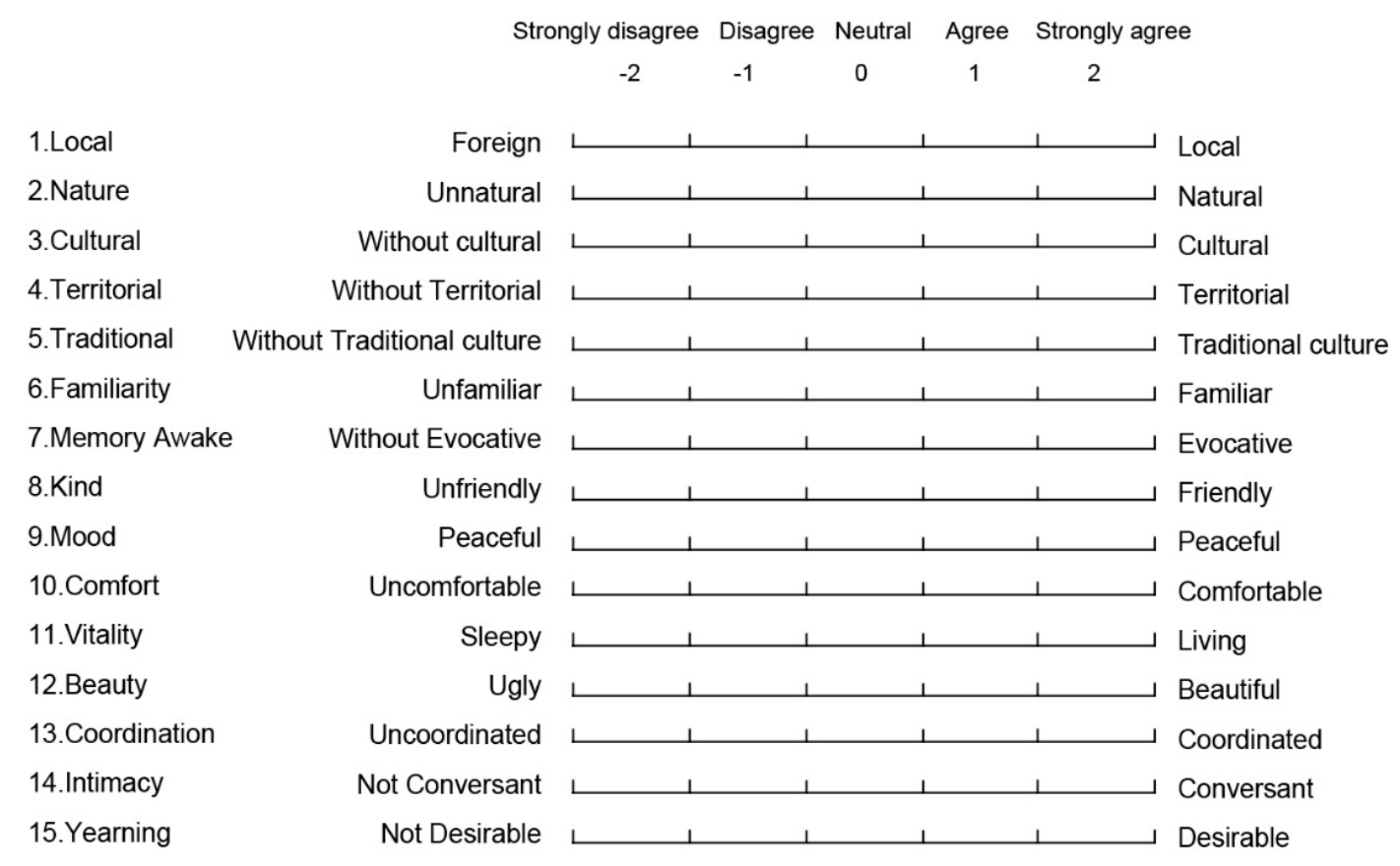

Figure 2. Semantic Difference Scales.

In order to enable a more scientific and effective quantitative evaluation of homesick landscape emotions, evaluation factors have to be filtered. Firstly, according to the literature (Table 2) on homesick landscape emotions as related to the visual environment, 45 groups of adjectives were identified which were considered suitable for describing homesick emotions as related to landscapes. These were handed to 18 experts and postgraduate students for a second filtering. Adjectives were limited to 15 pairs (Figure 2). 
Table 2. Evaluation factors associated with homesick landscapes.

\begin{tabular}{|c|c|c|c|}
\hline \multicolumn{2}{|c|}{ Construct } & Items & Supporting Literature \\
\hline \multicolumn{2}{|c|}{ Topophilia } & $\begin{array}{l}\text { Local; Nature; Cultural; } \\
\text { Territorial; Traditional; }\end{array}$ & {$[12,28,29]$} \\
\hline Place attachment & $\begin{array}{l}\text { Place identity } \\
\text { Place dependence } \\
\text { Place bonding }\end{array}$ & $\begin{array}{c}\text { Friendly; Memory; } \\
\text { Substitute; Satisfaction; } \\
\text { Familiarity; Belonging; }\end{array}$ & $\begin{array}{c}{[30,31]} \\
{[31,32]} \\
{[31,33-35]}\end{array}$ \\
\hline \multicolumn{2}{|c|}{ Nostalgia } & $\begin{array}{l}\text { Desire; Comfort; } \\
\text { Intimate; Mood; }\end{array}$ & [36-38] \\
\hline \multicolumn{2}{|c|}{ Aesthetics } & $\begin{array}{l}\text { Vitality; Harmonious; } \\
\text { Coordinated; Beautiful; }\end{array}$ & [38-40] \\
\hline
\end{tabular}

\subsubsection{Construction of Evaluation System and Determination of Index Weight}

In fact, not all of the 15 factors listed in Figure 1 are of the same importance, so we used the AHP method to calculate the index weight. AHP is a theory of measurement for dealing with quantifiable and intangible criteria that has been applied to numerous areas [29,30]. It helps with formulating the decision problem in the form of a hierarchical structure, based on decomposition, comparative judgment, and synthesis of priorities. In a hierarchy, the top level (Level I) reflects the overall objective, while the factors affecting the decision are represented in intermediate levels (Levels II and III). Once the hierarchy is constructed, a prioritization procedure being in order to determine the relative importance of the elements in each level of the hierarchy. The elements in each level are compared as pairs with respect to their importance in making the decision under consideration. After comparison matrices are created, relative weights are derived for the various elements. Composite weights are then determined by aggregating the weights throughout the hierarchy. Finally, check the consistency in the pair-wise comparison, whether a criterion can be used. IF consistency ratio $(C R)<0.10$, the degree of consistency is acceptable, but if $C R>0.10$, serious inconsistencies may exist, and the AHP may not yield meaningful results.

Applying to the AHP method, and on the basis of 15 factors, an evaluation index system was constructed (Table 3). Target layer I embodies effective quantification evaluation, target layer II includes 6 evaluation projects, while layer III represents 15 factors. A group of local experts were chosen and interviewed for evaluating these factors and determine the relative importance at each level. This generated the normalized matrix and. weights were produced (see Table 3), with the consistency being acceptable $(\mathrm{CR}=\mathrm{ACI} / \mathrm{ARI}=0.0328<0.1)$.

Table 3. The evaluation index system of the landscape and the respective weights assigned after the analytic hierarchy process (AHP) process.

\begin{tabular}{|c|c|c|c|c|c|}
\hline Target Layer (I) & Evaluation Pr & ct Layer (II) & Weight & Evaluation Factors (III) & Weight \\
\hline \multirow{6}{*}{$\begin{array}{c}\text { Emotion } \\
\text { evaluation }\end{array}$} & \multirow{2}{*}{ topophilia } & Nature & 0.3699 & $\begin{array}{c}\text { Local } \\
\text { Natural }\end{array}$ & $\begin{array}{l}0.1850 \\
0.1850\end{array}$ \\
\hline & & $\begin{array}{l}\text { Regional } \\
\text { Culture }\end{array}$ & 0.2818 & $\begin{array}{c}\text { Cultural } \\
\text { Territorial } \\
\text { Traditional }\end{array}$ & $\begin{array}{l}0.0460 \\
0.1520 \\
0.0837 \\
\end{array}$ \\
\hline & $\begin{array}{c}\text { Place } \\
\text { attachment }\end{array}$ & & 0.1439 & $\begin{array}{c}\text { Familiarity } \\
\text { Memory } \\
\text { Friendly }\end{array}$ & $\begin{array}{l}0.0480 \\
0.0480 \\
0.0480\end{array}$ \\
\hline & \multirow{2}{*}{ Nostalgia } & Psychology & 0.0577 & $\begin{array}{c}\text { Mood } \\
\text { Comfort }\end{array}$ & $\begin{array}{l}0.0096 \\
0.0481\end{array}$ \\
\hline & & Experience & 0.0577 & $\begin{array}{l}\text { Intimacy } \\
\text { Desirable }\end{array}$ & $\begin{array}{l}0.0433 \\
0.0144\end{array}$ \\
\hline & $\begin{array}{l}\text { Landscape } \\
\text { aesthetics }\end{array}$ & & 0.0889 & $\begin{array}{c}\text { Living } \\
\text { Beautiful } \\
\text { Harmonious }\end{array}$ & $\begin{array}{l}0.0264 \\
0.0480 \\
0.0145\end{array}$ \\
\hline
\end{tabular}




\subsection{Part 2 of the Scenic Visualisation and Data Processing}

\subsubsection{Selection of Dwellings Images and Trees}

The study covered multiple cities and counties in Fujian province, southeast of China, including for example, the cities of Fuzhou, Ningde, Longyan, Nanping, Quanzhou, and Sanming. Selected photos from these areas represent the typical rural residential landscape of different cultural types in Fujian province. Photos were selected from a wide range of photos from the area. First, selected photos needed to contain at least one residential dwelling. Second, each distinct region had to have a representative picture. Third, photos should also reflect variation in types of residential dwellings in the rural areas. Efforts were made to limit the presence of people, livestock, vehicles, or other interfering elements. A total of 36 photographs were selected for the study after evaluation by experts. The set of photos was then evaluated by eight experts of rural development, landscape architecture, ecology, and urban planning, from the perspective of representativeness and universality of the landscape in Fujian. This resulted in a final set of 20 photos used for the experiment.

Similar to previous photo evaluation methods, twelve local tree species were selected by ten plants experts, which were commonly found in these rural settings from a wide range of local plants in Fujian province. These were then added to the images using Photoshop.

\subsubsection{Scenic Visualisation Simulation}

The study applied a transdisciplinary method that combines the scenario approach, photorealistic visualization, and stakeholder participation to identify the interests of stakeholders in the future countryside [31]. Scenic visualization technology can create a series of different landscape images with the same background area as a tool to support landscape planning, for example by simulating changes to a landscape [32]. It can help make complex information clearer than written words or sounds can provide. It is widely used in future research, including trend analysis, forecasting, variable analysis, and sensitivity analysis [33-35].

In this research, Adobe Photoshop CS 6 software was used scenic visualization simulation. First of all, the 20 selected photos were categorized after comparison and screening. Then, three typical rural residential landscape photos were selected that were seen as representative for the area studied. The photos represent the tamped-soil dwellings (TSD) of the northern and western part of Fujian province, the white-walled dwellings (WWD) of the eastern part of the province, and the brick-walled dwellings (BWD) of the southern region.

Finally, trees were combined with three kinds of dwellings, constituting a new landscape configuration. In total, 39 photos were prepared, among them 36 photos with different types of configurations of buildings with trees and three photos without tress. Table 4 shows the landscape of Pyrus pyrifolia (Burm.f.) Nakai and three kinds of dwellings, while Figure 3 shows the images with scenes of the white-walled dwellings with trees.

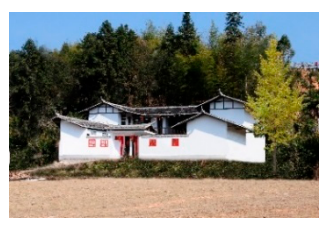

(a)

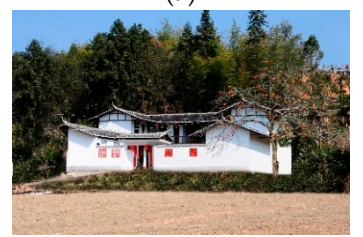

(d)

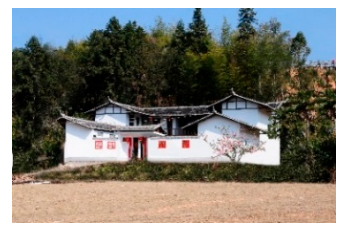

(b)

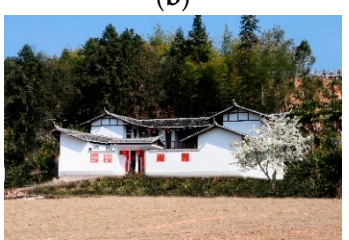

(e)

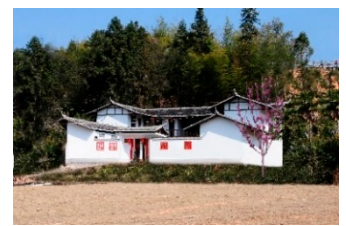

(c)

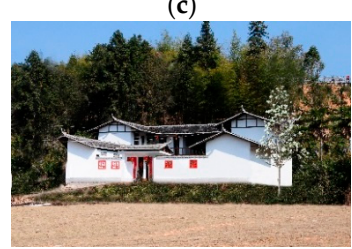

(f)

Figure 3. Cont. 


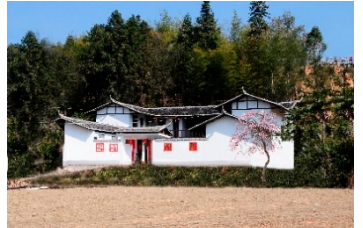

(g)

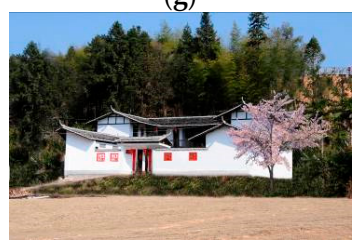

(j)

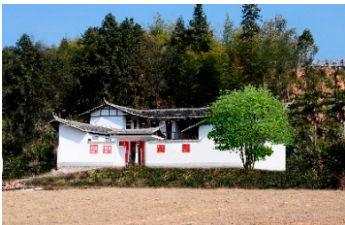

(h)

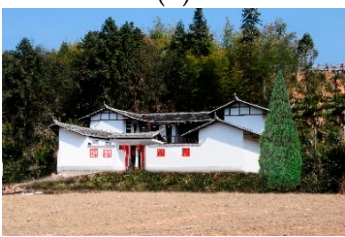

(k)

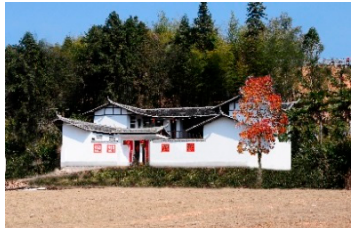

(i)

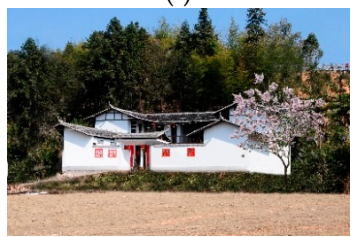

(1)

Figure 3. Visualisations of setting with white wall dwellings and different tree species. While wall dwelling scenes were manipulated by adding: (a) Ginkgo biloba L.; (b) Amygdalus persica L.; (c) Magnolia liliiflora Desr.; (d) Diospyros kaki Thunb.; (e) Pyrus pyrifolia (Burm.f.) Nakai; (f) Yulania denudata (Desr.) D. L. Fu; (g) Armeniaca mume Sieb.; (h) Osmanthus fragrans (Thumb.) Lour.; (i) Sapium sebiferum (L.) Roxb.; (j) Prunus campanulata Maxim.; (k) Juniperus chinensis L.; and (1) Paulownia tomentosa Steud.

Table 4. Pictures before/after processing (tree with three kinds of dwellings).

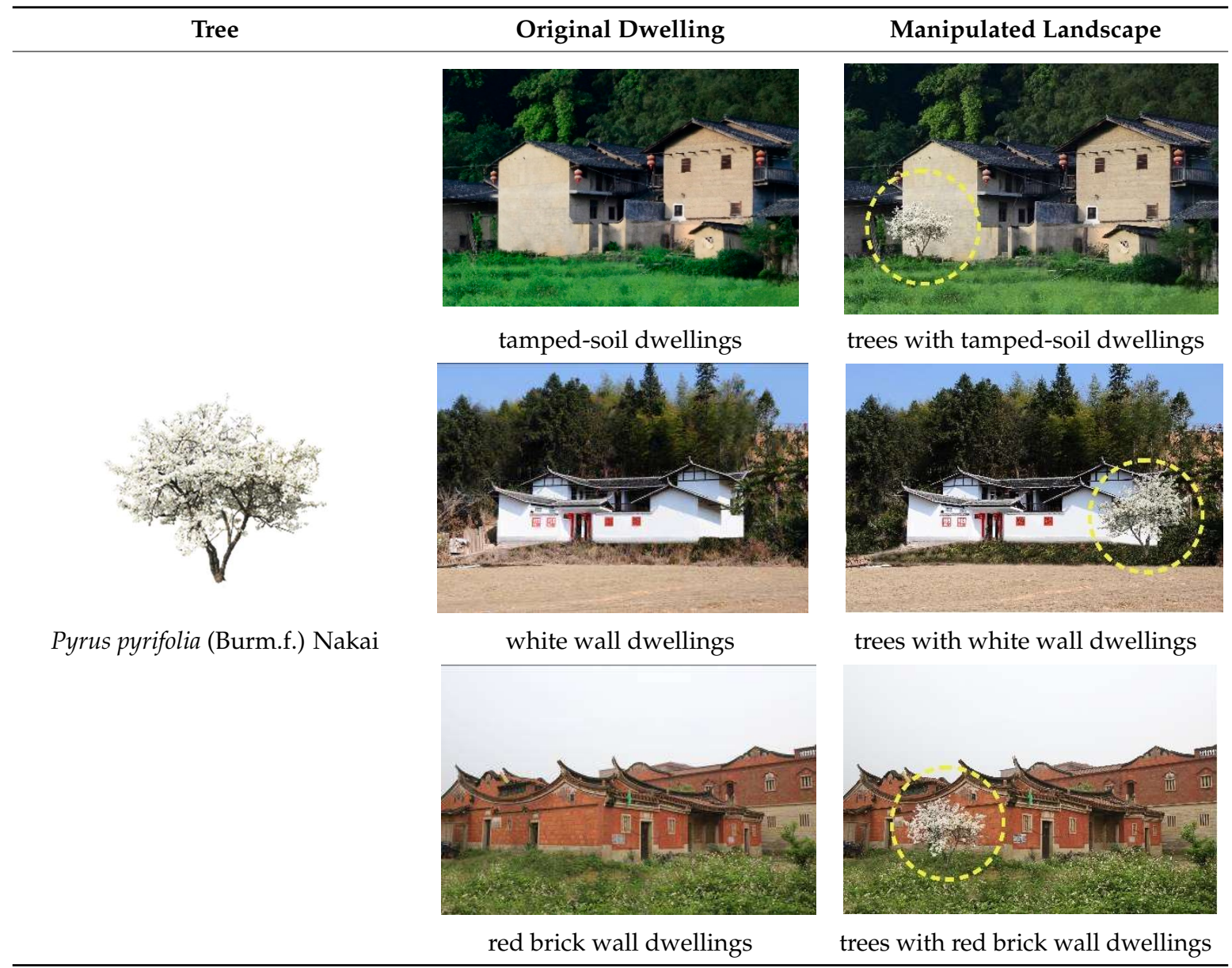




\subsubsection{Survey and Data Processing}

We selected 200 college students majoring in landscape architecture, urban planning, environment art design, animation, etc. for the experiment. Although this population represented some diversity, all respondents were university students, and most were familiar with countryside landscape and vegetation. Moreover, all students were born and raised in Fujian province, deriving from the northern, central, and southern parts of Fujian province. All had had at least half a year of life experience in a local village somewhere in the Fujian province.

First, the requirements of the evaluation tests were introduced to the participants, explaining the meaning of each adjective pair associated with the landscape environment. Second, the showing of pictures to the participants during scoring was repeated three times. The SD evaluation is based on the adjectives listed in Figure 1. A total of 200 questionnaires were issued, and 195 were received, of which 181 could be used (as some responses did not include ratings for all pictures or issued only identical ratings for all items), providing an effective questionnaire rate of $90.5 \%$. The respondents with valid questionnaires included slightly more women (50.3\%) than men $(49.7 \%)$, while just over half of the respondents has their residential background in cities (50.9\%) as compared to the countryside $(49.1 \%)$. Finally, SD scores were multiplied by AHP weight to obtain each participant's score for every picture. By using Excel 2016 and SPSS 24.0, the data were analysed using analysis of $t$-test, and cluster analysis was used to classify the different level of rural dwellings and tree configuration scenes.

\section{Results}

\subsection{Comparisons of Level of Place-Related Emotional Arousal before and after Picture Processing}

The study included scoring of the original scenes as well as those of the different simulated scenes after visual manipulation. Results show that compared to the original picture scene, respondents showed a stronger emotional reaction when shown most of the synthesized scenes (Table 5), for example when tree species such as A. persica, D. kaki, P. pyrifolia, A. mume, O. fragrans, S. sebiferum, and $P$. tomentosa were added. However, addition of some tree species, and specifically G. biloba, M. liliiflora, M. denudata, and J. chinensis, led to a lower emotional response. These results show that the addition of trees to the original landscape scene can evoke emotional responses.

The study used $t$-tests to further compare the changes in responses before and after landscape scene pictures. Table 5 shows that in the case of three different scenarios of tree configuration, most of the manipulated scenes evoked stronger emotional response levels, while the significance of changed responses varied. For the TSD picture, adding trees like G. biloba, A. persica, M. liliiflora, and J. chinensis to the configuration produced significant differences in emotional response, but especially M. denudata presented a very significant difference. The WWD configuration trees, like A. persica and P. pyrifolia, produced significant differences in emotional arousal level, but $P$. tomentosa presented a highly significant difference. For the BWD tree configuration, $D$. kaki and $P$. tomentosa produced significance differences, while A. persica, P. pyrifolia, and S. sebiferum all resulted in highly significant differences in emotional response. 
Table 5. T-test in tamped-soil dwellings (TSD), white-walled dwellings (WWD), and brick-walled dwellings (BWD) with tree configurations (before and after).

\begin{tabular}{|c|c|c|c|c|c|c|c|c|c|}
\hline \multirow[b]{2}{*}{ Tree Species } & \multicolumn{3}{|c|}{ TSD Configure Trees } & \multicolumn{3}{|c|}{ WWD Configure Trees } & \multicolumn{3}{|c|}{ BWD Configure Trees } \\
\hline & $\begin{array}{c}\text { Original } \\
\text { Picture }\end{array}$ & $\begin{array}{c}\text { Synthetic } \\
\text { Picture }\end{array}$ & $t$ & $\begin{array}{c}\text { Original } \\
\text { Picture }\end{array}$ & $\begin{array}{c}\text { Synthetic } \\
\text { Picture }\end{array}$ & $t$ & $\begin{array}{c}\text { Original } \\
\text { Picture }\end{array}$ & $\begin{array}{c}\text { Synthetic } \\
\text { Picture }\end{array}$ & $t$ \\
\hline 1. Ginkgo biloba L. & & -0.59 & 0.04 * & & 0.36 & 0.76 & & -1.07 & 0.16 \\
\hline 2. Amygdalus persica L. & & 1.94 & $0.03 *$ & & 2.49 & $0.03 *$ & & 1.04 & $0.01 * *$ \\
\hline 3. Magnolia liliiflora Desr. & & -0.16 & $0.03 *$ & & -0.32 & 0.24 & & 0.12 & 0.55 \\
\hline 4. Diospyros kaki Thunb. & & 2.45 & 0.48 & & 1.92 & 0.06 & & 1.51 & 0.01 * \\
\hline 5. Pyrus pyrifolia (Burm.f.)Nakai & & 2.05 & 0.28 & & 2.49 & $0.01 *$ & & 2.48 & $0.001 * *$ \\
\hline 6. Yulania denudata (Desr.) D. L. Fu & & -0.40 & $0.002 * *$ & & 0.49 & 0.37 & & 0.60 & 0.09 \\
\hline 7. Armeniaca mume Sieb. & 0.69 & 1.43 & 0.14 & 0.43 & 1.40 & 0.11 & -0.15 & 0.89 & 0.10 \\
\hline 8. Osmanthus fragrans (Thumb.) Lour. & & 1.89 & 0.21 & & 1.55 & 0.13 & & 1.54 & 0.19 \\
\hline 9. Sapium sebiferum (L.) Roxb. & & 1.82 & 0.44 & & 1.35 & 0.26 & & 1.09 & $0.01 * *$ \\
\hline 10. Prunus campanulata Maxim. & & 0.70 & 0.09 & & 0.69 & 0.76 & & 0.28 & 0.17 \\
\hline 11. Juniperus chinensis L. & & -1.16 & $0.047 *$ & & -0.96 & 0.27 & & -0.38 & 0.66 \\
\hline 12. Paulownia tomentosa Steud. & & 1.70 & 0.34 & & 2.03 & $0.00 * *$ & & 1.21 & $0.05 *$ \\
\hline
\end{tabular}

Note: ${ }^{*}: p<0.05,{ }^{* *}: p<0.01$. 


\subsection{Comparisons of Three Levels of Emotional Response Level after Picture Processing}

During photo manipulation of the rural landscape scenes, for each kind of dwelling 12 different Chinese native tree species were added to the scene. A T-test was used to further compare the 12 different scenes, with the level of emotional response showing differences as compared to the original scene. The WWD configured trees showed a high significant difference $(t=3.58$, $p=0.004<0.01)$, while TSD configured trees $(t=2.73, p=0.020<0.05)$ and BWD configured trees $(t=2.84, p=0.016<0.05)$ also achieved significant levels of emotional variability (Table 6$).$

Table 6. T-test results from three kinds of dwellings with trees added through photo manipulation.

\begin{tabular}{|c|c|c|c|c|c|c|}
\hline \multirow{3}{*}{ Scene } & \multicolumn{6}{|c|}{ Test Value $=0$} \\
\hline & \multirow{2}{*}{$t$} & \multirow{2}{*}{ df } & \multirow{2}{*}{$\begin{array}{c}\text { Sig. } \\
\text { (2-Tailed) }\end{array}$} & \multirow{2}{*}{$\begin{array}{c}\text { Mean } \\
\text { Difference }\end{array}$} & \multicolumn{2}{|c|}{$\begin{array}{l}95 \% \text { Confidence Interval } \\
\text { of the Difference }\end{array}$} \\
\hline & & & & & Lower & Upper \\
\hline TSD configured trees & 2.73 & 11 & $0.020 *$ & 0.97 & 0.19 & 1.76 \\
\hline WWD configured trees & 3.58 & 11 & $0.004^{* *}$ & 1.13 & 0.43 & 1.82 \\
\hline BWD configured trees & 2.83 & 11 & 0.016 * & 0.78 & 0.17 & 1.38 \\
\hline
\end{tabular}

Note: ${ }^{*}: p<0.05,{ }^{* *}: p<0.01$.

\subsection{Comparison of Emotional Response Level for Manipulated Landscape Scenes with Twelve Different Trees} Added to Dwellings

In the experiment, each native tree species was combined with three kinds of dwellings to synthesize new scenes. As can be seen in Table 7, adding M. denudate and S. sebiferum to different scenes showed a very significant emotional response. Responses to the adding of $M$. denudata $(t=16.37$, $p=0.004<0.01)$, S. sebiferum $(t=14.05, p=0.005<0.01)$, and A. persica, pear, osmanthus, and Prunus campanulata also generated significant differences, among them peach $(t=4.34, p=0.049<0.05)$, P. pyrifolia $(t=7.21, p=0.02<0.05)$, O. fragrans $(t=6.84, p=0.02<0.05)$, and $P$. campanulata $(t=6.66$, $p=0.02<0.05)$.

Table 7. $T$-test results for adding the 12 different tree species to the rural dwelling scenes.

\begin{tabular}{|c|c|c|c|c|c|c|}
\hline \multirow{3}{*}{ Tree Species } & \multicolumn{6}{|c|}{ Test Value $=0$} \\
\hline & \multirow{2}{*}{$t$} & \multirow{2}{*}{ df } & \multirow{2}{*}{$\begin{array}{c}\text { Sig. } \\
\text { (2-Tailed) }\end{array}$} & \multirow{2}{*}{$\begin{array}{c}\text { Mean } \\
\text { Difference }\end{array}$} & \multicolumn{2}{|c|}{$\begin{array}{l}95 \% \text { Confidence Interval } \\
\text { Associated with the Difference }\end{array}$} \\
\hline & & & & & Lower & Upper \\
\hline 1. Ginkgo biloba L. & -1.04 & 2 & 0.41 & -0.44 & -2.25 & 1.38 \\
\hline 2. Amygdalus persica L. & 4.34 & 2 & 0.049 * & 1.82 & 0.02 & 3.63 \\
\hline 3. Magnolia liliiflora Desr. & -0.92 & 2 & 0.45 & -0.12 & -0.68 & 0.44 \\
\hline 4. Diospyros kaki Thunb. & 7.21 & 2 & $0.02 *$ & 1.96 & 0.79 & 3.14 \\
\hline 5. Pyrus pyrifolia (Burm.f.) Nakai & 16.37 & 2 & $0.004 * *$ & 2.34 & 1.73 & 2.96 \\
\hline 6. Yulania denudata (Desr.) D. L. Fu & 0.73 & 2 & 0.54 & 0.23 & -1.14 & 1.60 \\
\hline 7. Armeniaca mume Sieb. & 6.84 & 2 & $0.02 *$ & 1.25 & 0.47 & 2.04 \\
\hline 8. Osmanthus fragrans (Thumb.) Lour. & 14.05 & 2 & $0.005^{* *}$ & 1.66 & 1.15 & 2.17 \\
\hline 9. Sapium sebiferum (L.) Roxb. & 6.66 & 2 & $0.02 *$ & 1.42 & 0.50 & 2.34 \\
\hline 10. Prunus campanulata Maxim. & 3.95 & 2 & 0.06 & 0.56 & -0.05 & 1.17 \\
\hline 11. Juniperus chinensis L. & -3.57 & 2 & 0.07 & -0.83 & -1.84 & 0.17 \\
\hline 12. Paulownia tomentosa Steud. & 6.90 & 2 & 0.02 & 1.64 & 0.62 & 2.67 \\
\hline
\end{tabular}

\subsection{Cluster Analysis of Emotional Responses to the Manipulated Rural Dwelling Scenes}

Cluster analysis of the results looked at the emotional response levels related to landscape scenes in terms of presence of different dwelling types and tree species. For TSD with added trees, emotional response was divided into three grades (Figure 4a), with the highest emotional 
response being associated with P. pyrifolia, A. persica, O. fragrans, S. sebiferum, P. tomentosa, and A. mume. The medium level of response was associated with $P$. campanulate, while the third and lowest level of emotional response was linked with G. biloba, M. liliiflora, M. denudata, and J. chinensis. For WWD with added trees A. persica, P. pyrifolia, P. tomentosa, D. kaki, O. fragrans, A. mume, and S. sebiferum resulted in the highest level of emotional response (Figure $4 \mathrm{~b}$ ). The second, medium level of response was associated with P. campanulata, M. denudate, and G. biloba, while the third and lowest level of response was generated by scenes with M. liliiflora and J. chinensis added. For BWD scenes with added trees, the cluster with the highest level of response (Figure $4 \mathrm{c}$ ) included P. pyrifolia. The second, medium level of response was generated by D. kaki, O. fragrans, A. persica, S. sebiferum, P. tomentosa, A. mume, and M. denudate. Finally, the third, lower level of emotional response was associated with M. liliiflora, P. campanulata, J. chinensis, and G. biloba.

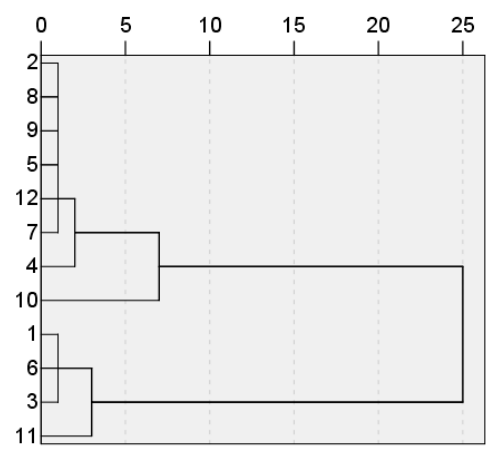

(a)

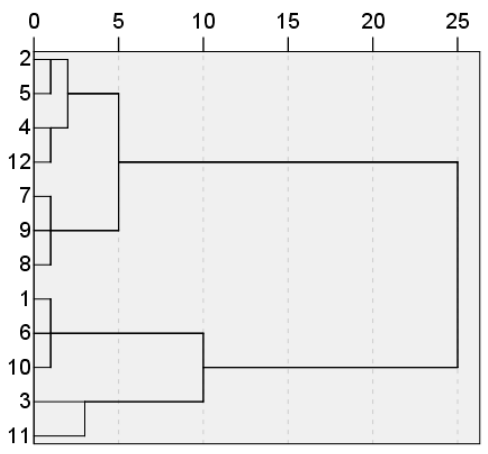

(b)

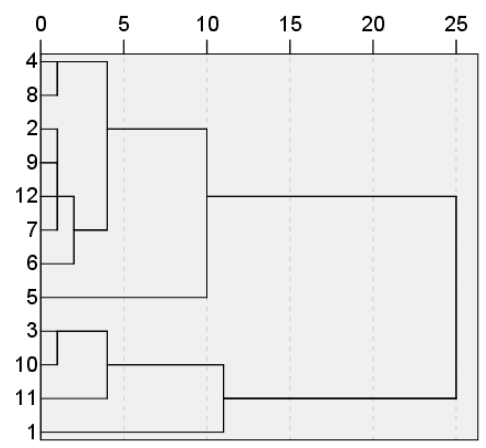

(c)

Figure 4. Cluster analysis: (a) TSD Cluster analysis; (b) WWD Cluster analysis; (c) BWD Cluster analysis. Note: 1. G. biloba; 2. A. persica; 3. M. liliiflora; 4. D. kaki; 5. P. pyrifolia; 6. Y. denudate; 7. A. mume; 8. O. fragrans; 9. S. sebiferum; 10. P. campanulate; 11. J. chinensis; 12. P. tomentosa.

\section{Discussion}

\subsection{Combination Scenes Change Homesickness Emotion Response}

Overall, study results indicate that the adding of trees to dwelling scenes will change people's homesickness emotional response. This study further confirms that the addition of the right vegetation elements to countryside scenes with dwellings facilitates such a response. Previous studies have suggested that plants can help raise emotional responses to places [36-38]. Moreover, some studies have suggested that individuals can build emotional connections with landscapes, and experience emotional transfer and comfort from the familiar landscape scenes [39,40]. This holds true for dwellings and trees deriving from the local area under study. However, this is consistent with our hypothesis; the combination to these pictures significantly change the respondents' emotion.

From the perspective of psychology and iconology it is possible to transfer emotional emotions to a new scene. Lee and Allen note that it may be possible to develop strong feelings for a place one has never visited [41]. Thus, it can be inferred that when shown simulated images with a new landscape scene with the combination of elements, individuals will compare the scene with their previous experiences, which can be reminiscent of the past rural environment, which then can lead to emotional integration and transfer from similar previous locations. Some who sunder ties with past landscapes can find continuity in furnishing their new landscapes with real or symbolic replicas of departed scenes to assuage nostalgia [42]. Rural construction and development irresistible changed the original appearance of the countryside. The new living environments are completely new. Brennan-Horley and colleagues suggest that grafting an image onto an environment is an efficient and effective means to manage place attachment and identity [43].

In this study, the original scenes evoked a low level of emotional response, and the addition of unidentified vegetation to those dwellings lead to even lower emotional response level than for 
the original. Though those elements are common, inappropriate combinations result in the image being rated lower than before. These results show that not all combinations can arouse homesickness feelings. The respondents' homesickness sentiment is targeted, and the people do not associate emotions with inappropriate landscape scenes. Two possible explanations can be offered to explain this phenomenon. First, some of those common trees are usually not planted in the vicinity of dwellings. In other words, the shown configuration is not common. Second, people have a clear view of the homesickness landscape of their living environment and they also have a certain degree of style recognition. This is not about a simple aesthetic identity about landscape, rather it is a deeply ingrained perception that people may not even be aware of. We could relate this to the term "collective memory" as used by sociologists and social psychologists, i.e., the memory shared by groups or societies, or "social memory". We can therefore consider these types of landscape as the public's prototype of homesickness landscape in this area. Similar to research about prototype landscape, a previous study of landscape composition and childhood memory suggests, among those elements of the landscape, trees are of the most impressive in people's minds. On the other hand, buildings are the most impressive element in the study of landscape evaluation and spatial cognition [44]. Further studies are necessary to achieve greater understanding of the emotion response to different combinations of landscape elements.

\subsection{Different Combinations Lead to Different Homesickness Emotional Response}

Another perhaps surprising finding of this study was that adding a tree to the three dwellings led to higher emotional response for some, but a lower one for others. Some trees scored lower when combined with all three dwellings. There are three possible explanations for this. First, these three dwellings are representative of different cultures and lifestyles. While combined with trees, it becomes a landscape which is full of different and perhaps contradicting information. Some scenes are familiar in an individual's mind, owing to some trees being frequently used around dwellings while others are not (e.g., J. chinensis). Trees like M. liliiflora, M. denudate, and S. sebiferum are not very often used around dwellings, which results in less familiar scenes that do not evoke a strong emotional response.

Second, some trees are the representation of traditional festivals related to homesickness. A. mume is a typical tree associated with the Spring Festival, while $O$. fragrans is a representative species of the Mid-Autumn Festival. Researchers demonstrated that festivals may contribute to a sense of place [45], and arouse evoking homesickness [46]. Thus, homesickness tends to be high during those festival. Furthermore, the "Cognitive Survey of Contemporary Homesickness" Annual Report 2016, show that the Spring Festival is indeed the easiest time to evoke people's thoughts about their hometown, followed by the Mid-Autumn Festival, while the Ching Ming Festival and the Double Ninth Festival evoke a much smaller level of homesickness than the former two. The report also suggests that autumn and spring more easily arouse homesickness compared to summer and winter. When people see G. biloba and S. sebiferum (both deciduous trees that shed their leaves in autumn), feelings of homesickness are evoked. McClinchey and Carmichael note that the meaning of place is influenced by festival experiences, and the personal sense of place is a reflective state or nostalgia for past experience [46].

Third, as far as memory is concerned, in traditional villages, fruit trees were planted at home because of food shortages. For example, A. persica, D. kaki, and P. pyrifolia, produce peaches, persimmons, respectively pears, which were all major fruits in the past. These trees are associated with happy childhood memories and thus evoke high levels of homesickness [47]. This is also related to place identity. Relph (2001) believes that where we experience the meaningful events of our existences, place identity emerges and the original 'cold material space' will be transformed into a place that carries emotion and meaning [48]. Similarly, Stedman (2003) stated that personal experience is the very element that turns "space into place" [49]. As Tuan (1977) observed, places involve meanings and values that facilitate intimate connections with particular geographical areas. 


\subsection{Implications}

The findings of this study provide theoretical support for the development of homesickness landscapes in rural areas-areas of current interest to e.g., the Chinese government. The current study supports the argument that people may have emotional responses linked to feelings of homesickness to a place with familiar landscape scenes [50,51]. These scenes can evoke people's memories and longing for a better life [52,53]. This study further demonstrated that certain landscape configurations can significantly change one's homesickness emotional response. We analysed the homesickness emotional response level for twelve different tree species in relation to three dwelling types, and results can provide a useful reference for future landscape construction and tree selection. The methods proposed in this study may also be used to assess whether environmental construction of rural landscapes satisfies emotional requirements, and it can influence the assessment of landscape construction. With better understanding of the role of vegetation elements, managers and planners can develop better solutions which combine people's preferences, emotional needs, and landscape construction at the same time. This will help build stronger place attachment, place identity, and can foster greater countryside sustainability through stronger people-rural landscape connections [54]. Moreover, this study argues for focusing on local characteristics as symbols of specific rural areas as well as the spirit of the place, both in sustainable rural development and enhancing sustainable tourism.

\subsection{Limitation and Future Research}

Several limitations of this study need to be acknowledged. First, our study used visualization to create the landscape scenes. It is possible, however, that emotional responses can be evoked by other information or senses other than the visual such as smell, taste, or sound. Additional measures are needed for a more comprehensive understanding of the phenomena studied. The second limitation is that our study only focused on a rural area in the southeast of China, and thus findings may only relate to this specific area. Similar work can expand to urban and suburban districts, to further study the relationship between vegetation and dwellings elements in communities, with the ultimate aim of further improving the settlement of human beings. The third limitation is that our study is based on the relationship between a certain person or a specific group of people, specific rural scenes, and specific trees. As for undergraduate and graduate students participating in the study: all come from Fujian province and showed considerable similarity in their survey responses. However, researchers have suggested that various socio-economic and socio-cultural groups, such as country-dwellers, farmers, experts, and visitors, may have a very similar sense of place or landscape perceptions for a certain setting $[55,56]$. Other scholars have also suggested that people with different attributes showed more commonality in landscape perceptions within the same area [44]. At least this could imply that the outcome of the study is a representation of regional university students' homesickness feelings related to landscapes in rural areas. Therefore, future research on this topic could focus on different cultural backgrounds or different generation groups while observing different scenes.

\section{Conclusions}

By analysing the role of trees in rural residential landscape settings that foster place attachment and homesickness, findings from this study can be used in the quest for more sustainable rural landscapes in China. We provide a more intuitive virtual image evaluation method of landscape planning and it is easier for the public to involve, where traditional methods are opaque and abstract, and often fail to ignite public passion. This study preliminarily, and for the specific context of the study confirms the following: (1) adding plant elements (and trees in particular) can cause emotional response changes in the landscape; (2) only certain vegetation can awaken homesickness, while inappropriate plants can reduce positive emotions; (3) different buildings have different matching vegetation that enhances homesickness; (4) trees do not necessarily evoke an emotional boost for all building types; 
and (5) in the case of native trees with cultural, edible, and ornamental functions, the emotional response level will typically be high.

The study provides new insights for landscape architects, landscape planners, and other professionals with respect to understanding the emotional contributions of integrating specific landscape elements. The work also provides a new reference for future construction activities in the countryside. By gaining an understanding of these aspects, decision makers and planners can raise their awareness of the importance of the design process when developing rural communities as well as during reconstruction of settlements after disasters. Moreover, the present study enriches knowledge about the role of homesickness in relation to construction and rural development. We hope that this new knowledge can contribute to a more proactive sustainable landscape planning rather than the often used practice of reacting and responding to emerging conflicts and issues.

Author Contributions: S.H. conceived and designed the study; S.H., W.F., J.D. and Z.C. analyzed the data and discussed the results; Z.Z. and J.Q. discussed the results; S.H. helped write the paper; C.K.v.d.B. discussed study design and presentation of results, and helped write the paper.

Funding: This research was funded by Public Interest Program of Chinese Ministry of State Forestry (No. 201404301; 201404315), and Public Program of National Engineering Research Center for the Forest Park (No. PTJH1500218).

Acknowledgments: We express special thanks to the colleagues who helped carry out the survey on site. All photos used in this project were taken by the first author.

Conflicts of Interest: The authors declare no conflict of interest.

\section{References}

1. Tang, C.; He, Y.; Zhou, G.; Zeng, S.; Xiao, L. Optimizing the spatial organization of rural settlements based on life quality. J. Geogr. Sci. 2018, 28, 685-704. [CrossRef]

2. Jung, H.; Ryu, J. Sustaining a Korean Traditional Rural Landscape in the Context of Cultural Landscape. Sustainability 2015, 7, 11213-11239. [CrossRef]

3. Agnoletti, M. Rural landscape, nature conservation and culture: Some notes on research trends and management approaches from a (southern) European perspective. Landsc. Urban Plan. 2014, 126, 66-73. [CrossRef]

4. Junren, W. Economic Globalization and Cultural Pluralism. Soc. Sci. China 2001, 2, 38-48.

5. Ryan, R.L. Preserving rural character in New England: Local residents'perceptions of alternative residential development. Landsc. Urban Plan. 2002, 61, 19-35. [CrossRef]

6. Yu, H.; Verburg, P.H.; Liu, L.; Eitelberg, D.A. Spatial Analysis of cultural heritage landscapes in rural China: Land use change and its risks for conservation. Environ. Manag. 2016, 57, 1304-1318. [CrossRef] [PubMed]

7. Morse, C.; Mudgett, J. Longing for landscape: Homesickness and place attachment among rural out-migrants in the 19th and 21st centuries. J. Rural Stud. 2017, 50, 95-103. [CrossRef]

8. Raymond, C.M.; Brown, G.; Weber, D. The measurement of place attachment: Personal, community, and environmental connections. J. Environ. Psychol. 2010, 30, 422-434. [CrossRef]

9. Shaoming, L. Temporal and spatial image of Chinese homesickness and its urban humanistic renaissance. Mod. Urban Res. 2016, 8, 2-10.

10. Stephan, E.; Sedikides, C.; Wildschut, T. Mental travel into the past: Differentiating recollections of nostalgic, ordinary, and positive events. Eur. J. Soc. Psychol. 2012, 42, 290-298. [CrossRef]

11. Nielsen-Pincus, M.; Hall, T.; Force, J.E.; Wulfhorst, J.D. Sociodemographic effects on place bonding. J. Environ. Psychol. 2010, 30, 443-454. [CrossRef]

12. Tuan, Y. Topophilia: A Study of Environmental Perception, Attitudes, and Values; Columbia University Press: New York, NY, USA, 1974.

13. Scopelliti, M.; Tiberio, L. Homesickness in university students: The role of multiple place attachment. Environ. Behav. 2010, 42, 335-350. [CrossRef]

14. Chow, K.; Healey, M. Place attachment and place identity: First-year undergraduates making the transition from home to university. J. Environ. Psychol. 2008, 28, 362-372. [CrossRef] 
15. Lewicka, M. Place attachment: How far have we come in the last 40 years? J. Environ. Psychol. 2011, 31, 207-230. [CrossRef]

16. Kyle, G.; Graefe, A.; Manning, R.; Bacon, J. Effects of place attachment on users' perceptions of social and environmental conditions in a natural setting. J. Environ. Psychol. 2004, 24, 213-225. [CrossRef]

17. Feldman, R. Psychological Bonds with Home Places in a Mobile Society; Regimes of Closure; University of Illinois: Chicago, IL, USA, 1989; p. 191.

18. Bonaiuto, M.; Aiello, A.; Perugini, M.; Bonnes, M.; Ercolani, A.P. Multidimensional perception of residential environment quality and neighbourhood attachment in the urban environment. J. Environ. Psychol. 1999, 19, 331-352. [CrossRef]

19. Scannell, L.; Gifford, R. The experienced psychological benefits of place attachment. J. Environ. Psychol. 2017, 51, 256-269. [CrossRef]

20. Dale, A.; Ling, C.; Newman, L. Does place matter? Sustainable community development in three Canadian communities. Ethics Place Environ. 2008, 11, 267-281. [CrossRef]

21. Muslim, Z. Design Transformation based on nature and identity formation in the design of landscape elements. Environ. Behav. Proc. J. 2016, 1, 189-196. [CrossRef]

22. Roncken, P.A. Rural landscape anatomy: Public space and civil yards in Dutch rural landscapes of the future. J. Landsc. Arch. 2006, 1, 8-21. [CrossRef]

23. Dallas, P. Sustainable environments: Common wood pastures in Norfolk. Landsc. Hist. 2010, 31, 23-36. [CrossRef]

24. Lehmann, A. Von Menschen und Bäumen: Die Deutschen und IHR Wald; Rowohlt Verlag GmbH: Berlin, Germany, 1999.

25. Casakin, H.; Reizer, A. Place attachment, residential satisfaction, and life satisfaction: Traditional and renewed kibbutz. Hum. Behav. Soc. Environ. 2017, 27, 639-655. [CrossRef]

26. Soini, K.; Vaarala, H.; Pouta, E. Residents' sense of place and landscape perceptions at the rural-urban interface. Landsc. Urban Plan. 2012, 104, 124-134. [CrossRef]

27. Solley, C.M.; Messick, S.J. Probability, learning, the statistical structure of concepts, and the measurement of meaning. Am. J. Psychol. 1957, 70, 161-173. [CrossRef] [PubMed]

28. Ploder, A.; Eder, A. Semantic Differential, in International Encyclopedia of the Social E Behavioral Sciences, 2nd ed.; Elsevier: Oxford, UK, 2015; pp. 563-571.

29. Vargas, L.G. An overview of the analytic hierarchy process and its applications. Eur. J. Oper. Res. 1990, 48, 2-8. [CrossRef]

30. Saaty, T.L. The Analytic Hierarchy Process; McGraw-Hill: New York, NY, USA, 1980.

31. Tress, B.; Tress, G. Scenario visualisation for participatory landscape planning-A study from Denmark. Landsc. Urban Plan. 2003, 64, 161-178. [CrossRef]

32. Lange, E.; Hehl-Lange, S.; Brewer, M.J. Scenario-visualization for the assessment of perceived green space qualities at the urban-rural fringe. J. Environ. Manag. 2008, 89, 245-256. [CrossRef] [PubMed]

33. Lange, E. The limits of realism: Perceptions of virtual landscapes. Landsc. Urban Plan. 2001, 54, $163-182$. [CrossRef]

34. Lin, E.; Shaad, K.; Girot, C. Developing river rehabilitation scenarios by integrating landscape and hydrodynamic modeling for the Ciliwung River in Jakarta, Indonesia. Sustain. Cities Soc. 2016, 20, 180-198. [CrossRef]

35. Rid, W.; Haider, W.; Ryffel, A.; Beardmore, A.B. Visualisations in Choice Experiments: Comparing 3D Film-sequences and Still-images to Analyse Housing Development Alternatives. Ecol. Econ. 2018, 146, 203-217. [CrossRef]

36. Kaltenborn, B.R.P.; Bjerke, T. Associations between Landscape Preferences and Place Attachment: A study in Røros, Southern Norway. Landsc. Res. 2002, 27, 381-396. [CrossRef]

37. Mandondo, A. Trees and spaces as emotion and norm laden components of local ecosystems in Nyamaropa communal land, Nyanga District, Zimbabwe. Agric. Hum. Values 1997, 14, 353-372. [CrossRef]

38. Lies, M.M.; Kang, M.; Sample, R.K. Place attachment and design features in a rural senior cohousing community. Hous. Soc. 2017, 44, 41-63. [CrossRef]

39. Cheng, C.; Kuo, H. Bonding to a new place never visited: Exploring the relationship between landscape elements and place bonding. Tour. Manag. 2015, 46, 546-560. [CrossRef] 
40. Riley, R.B. Attachment to the Ordinary Landscape, in Place Attachment; Springer US: Boston, MA, USA, 1992; pp. 13-35.

41. Changuklee, C.; Allen, L. Understanding individuals' attachment to selected destination: An application of place attachment. Tour. Anal. 1999, 4, 173-185.

42. Lowenthal, D. Past time, present place: Landscape and memory. Geogr. Rev. 1975, 65, 1-36. [CrossRef]

43. Brennan-Horley, C.; Connell, J.; Gibson, C. The Parkes Elvis Revival Festival: Economic development and contested place identities in rural Australia. Geogr. Res. 2007, 45, 71-84. [CrossRef]

44. Wang, Z.J.; Hu, L.H.; Li, S.H. Investigation on Influences of Prototype Landscape on People's Environmental Perceptions. Chin. Landsc. Arch. 2010, 7, 46-48.

45. McClinchey, K.A. Conceptualizing Sense of Place through Multi-Ethnic Narratives at a Multicultural Festival. Available online: https: / / scholarworks.umass.edu/cgi/viewcontent.cgi?article=1652\&context=ttra (accessed on 29 October 2018).

46. McClinchey, K.A.; Carmichael, B.A. The Tourism and Leisure Experience: Consumer and Managerial Perspectives. In The Role and Meaning of Place in Cultural Festival Visitor Experiences; Channel View Publications: Bristol, UK, 2010; pp. 59-80.

47. He, B.; Zhu, J. Constructing community gardens? Residents' attitude and behaviour towards edible landscapes in emerging urban communities of China. Urban For. Urban Green. 2018, 34, 154-165. [CrossRef]

48. Relph, E. Place and Placelessness, 2nd ed.; Pion: Forest Row, UK, 1976; Volume 1.

49. Stedman, R.C. Sense of place and forest science: Toward a program of quantitative research. For. Sci. 2003, $49,822-829$.

50. Manzo, L.C. Beyond house and haven: Toward a revisioning of emotional relationships with places. J. Environ. Psychol. 2003, 23, 47-61. [CrossRef]

51. Sharpley, R.; Jepson, D. Rural tourism: A spiritual experience? Ann. Tour. Res. 2011, 38, 52-71. [CrossRef]

52. Christou, P.; Farmaki, A.; Evangelou, G. Nurturing nostalgia? A response from rural tourism stakeholders. Tour. Manag. 2018, 69, 42-51. [CrossRef]

53. Duan, Z.; Xu, X. An Analysis of population return from the perspective of rural urbanization. Sustain. Environ. 2017, 2, 309. [CrossRef]

54. He, B.; Zhao, D.; Zhu, J.; Darko, A.; Gou, Z. Promoting and implementing urban sustainability in China: An integration of sustainable initiatives at different urban scales. Habitat Int. 2018, in press. [CrossRef]

55. Rogge, E.; Nevens, F.; Gulinck, H. Perception of rural landscapes in Flanders: Looking beyond aesthetics. Landsc. Urban Plan. 2007, 82, 159-174. [CrossRef]

56. Stedman, R.C. Understanding place attachment among second home owners. Am. Behav. Sci. 2016, 50, 187-205. [CrossRef]

(C) 2018 by the authors. Licensee MDPI, Basel, Switzerland. This article is an open access article distributed under the terms and conditions of the Creative Commons Attribution (CC BY) license (http:/ / creativecommons.org/licenses/by/4.0/). 